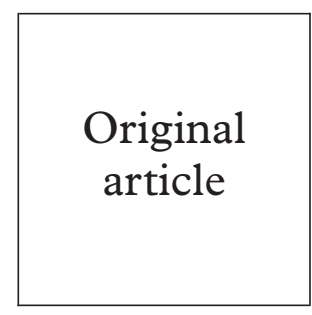

Original article

Division of Infectious

Diseases, Johns

Hopkins University,

Baltimore, MD, USA

G R Burstein

J M Zenilman

C A Gaydos

M R Howell

T C Quinn

Department of

Biostatistics

M Diener-West

Baltimore City Health

Department,

Baltimore, MD, USA

W Brathwaite

National Institute of Allergy and Infectious Diseases, National Institute of Health,

Bethesda, MD, USA

T C Quinn

Correspondence to: Gale Burstein, MD, MPH, Centers for Disease Control and Prevention, Division of Adolescent and School Health, 4770 Buford Hwy,

NE, MS K-33, Atlanta, GA

30341, USA

gib5@cdc.gov

Accepted for publication 14 November 2000

\title{
Predictors of repeat Chlamydia trachomatis infections diagnosed by DNA amplification testing among inner city females
}

Gale R Burstein, Jonathan M Zenilman, Charlotte A Gaydos, Marie Diener-West, M René Howell, Wayne Brathwaite, Thomas C Quinn

Objective: To describe the epidemiology of prevalent and incident chlamydia infection in order to assess the appropriate interval for chlamydia screening; and to identify risk factors predictive of infection and repeat infections.

Design: Prospective longitudinal study of a consecutive sample of 3860 sexually active females aged 12-60 years tested for $C$ trachomatis by polymerase chain reaction in Baltimore City clinics during 11904 patient visits over a 33 month period.

Results: Chlamydia prevalence, incidence, and frequency to diagnosis of infection varied by age. Among 2073 females <25 years, chlamydia infection was found in $31.2 \%$. The median times to first and repeat incident infections were 7.0 months and 7.6 months, respectively. Among 1787 females $\geqslant 25$ years, chlamydia infection was found in $9.6 \%$. Median times to first and repeat incident infections were 13.8 months and 11.0 months, respectively. Age <25 years yielded the highest risk of infection.

Conclusions: Since a high burden of chlamydia was found among mostly asymptomatic females $<25$ years in a spectrum of clinical settings, we recommend chlamydia screening for all sexually active females $<25$ years at least twice yearly.

(Sex Transm Inf 2001;77:26-32)

Keywords: chlamydia; adolescents; sexually transmitted diseases

\section{Introduction}

Chlamydia is the most common reportable bacterial sexually transmitted disease (STD) in the United States, with an estimated three million cases annually ${ }^{12}$ and is the most common preventable cause of serious gynaecological problems, such as tubal factor infertility, ectopic pregnancy, and chronic pelvic pain. ${ }^{3-6}$ Furthermore, among all women, sexually active adolescents are at highest risk for chlamydia infection and its sequelae. ${ }^{7-9}$

Because of the potential adverse outcomes following infection, since 1993, the Centers for Disease Control and Prevention (CDC) has recommended screening all sexually active females under the age of 20 years and women 20-24 years with sexual risk behaviours for chlamydia genital infection whenever undergoing a pelvic examination. ${ }^{10}$ The development of highly sensitive nucleic acid amplification tests has facilitated increased screening, since they can be performed using a cervical, self administered vaginal swab, or urine sample, alleviating the need for a pelvic examination for screening asymptomatic females. ${ }^{11-16}$

This change in the clinical paradigm and the increased sensitivity of these tests has prompted a re-evaluation of the screening strategy. The issue of who should be screened and how frequently warrants revisiting. We previously reported high chlamydia prevalence and incidence rates among Baltimore City adolescents (a subset of females in this analysis). ${ }^{7}$ However, that analysis was limited to data with females $<20$ years old. In this study we evaluated longitudinal data collected on sexually active females age $12-60$ years having at least two clinic visits with nucleic acid amplification test screening for chlamydia. Our objectives were to describe the epidemiology of chlamydia in females and to identify risk factors which predict current and repeat infections.

\section{Methods}

STUDY SAMPLE

Chlamydia screening in Baltimore family planning (FP), sexually transmitted disease (STD), and school based health centres is a component of the US Public Health Service Region III Infertility Prevention Project. ${ }^{77}$ This analysis included data collected from participating sites from 1 January 1994 to 30 September 1996. Informed consent for care was obtained from all patients attending the participating Baltimore City Health Department (BCHD) FP (two), STD (two), and school clinics (five). The study was approved by the institutional review boards of the BCHD and Johns Hopkins University.

\section{DATA COLLECTION}

Demographic and behavioural data were routinely collected using a standardised form on all women tested for chlamydia at each visit. Race or ethnicity and date of birth were recorded according to patients' self description. Reasons for chlamydia test/examination were coded as mutually exclusive categories and included (1) STD contact regardless of symptoms, (2) evaluation of any STD related 
Table 1 First clinic visit characteristics of 3860 sexually active females tested for $C$ trachomatis by PCR reaction in at least two clinic visits $>30$ days apart in Baltimore family planning, sexually transmitted diseases, and school based clinics, fan 1994-Sept 1996

\begin{tabular}{lc}
\hline Variables & $\begin{array}{c}\text { Females } \\
(n=3860) \\
(\%)\end{array}$ \\
\hline Age (years) & \\
$12-24$ & 53.4 \\
$25-60$ & 46.6 \\
Reason for test & \\
STD contact & 13.0 \\
STD symptoms & 22.3 \\
"Other" & 4.2 \\
Screening & 60.5 \\
Clinic type & 43.0 \\
Family planning & 49.3 \\
STD & 7.7 \\
School & \\
Risk behaviours & 75.5 \\
Inconsistent condom use & 13.6 \\
$>1$ sex partner & 14.5 \\
New sex partner & 3.9 \\
Self reported STD history & 36.9 \\
Previous syphilis infection & \\
Previous GC/CT infection &
\end{tabular}

${ }^{\star} \mathrm{GC}=$ Neisseria gonorrhoeae $; \mathrm{CT}=$ Chlamydia trachomatis.

symptoms, such as vaginal discharge or lower abdominal pain, (3) STD screening without symptoms, such as for a routine physical examination or for STD concerns without symptoms (that is, "I just want to get checked out"), and (4) reason "other" than above, such as injury, viral illness complaints, or refill of contraception method. Previous STD history was by self report and included (1) a previous syphilis infection, and (2) a previous gonorrhoea and/or chlamydia infection. Sexual risk behaviours in the 90 days before testing also were by self report and included having a new partner, multiple partners, or inconsistent condom use.

Patients with clinical signs of infection, who were diagnosed with gonorrhoea or chlamydia cervicitis, or who had sexual contact with a partner with symptoms or a diagnosis of urethritis received treatment including either doxycycline $100 \mathrm{mg}$ twice daily for 7 days or a single $1.0 \mathrm{~g}$ dose of azithromycin before leaving the clinic. All patients with a positive chlamydia test at the STD and FP clinics were notified by telephone or mail and requested to return for treatment (if not already provided). Patients at the school based health centres were usually available on site to receive test results and treatment. All infected patients were advised to refer their partners for treatment and to abstain from sexual intercourse for 7 days following complete treatment of both patient and all current sex partners.

\section{LABORATORY METHODS}

Cervical specimens were routinely obtained by clinicians using a standard protocol when a pelvic examination was performed, regardless of patient age and symptoms. Urine specimens were obtained when no pelvic examination was performed. Chlamydia tests were performed at the Johns Hopkins University chlamydia research laboratory by polymerase chain reaction (PCR) (Amplicor at Roche Diagnostic Systems, Branchberg, NJ, USA) have been previously described. ${ }^{13}$
SUBJECTS

From 1 January 1994 to 30 September 1996, there were 21269 clinic visits associated with chlamydia testing. Among 21269 visits, $11904(56 \%)$ were eligible for study inclusion. These 11904 visits $>30$ days apart were made by 3860 females $12-60$ years of age. Two hundred and eight $(1.0 \%)$ were male and were excluded from further analysis. Sixty three observations $(0.3 \%)$ were excluded where either non-nucleic acid chlamydia testing was done or test results were not available. A total of 1020 observations (4.8\%) with unknown or unavailable demographic and/or behavioural information were excluded. We excluded 1304 observations $(6.1 \%)$ in visits less than 30 days apart in order to remove the possibility of including in the analysis more than one positive test per unique infection. Finally, 57 observations $(0.3 \%)$ of females aged less than 12 years, or more than 60 years of age were excluded and 6770 observations $(31.8 \%)$ were excluded for subjects with only one chlamydia test during the study period.

\section{DEFINITIONS}

An incident case of chlamydia was defined as a positive PCR chlamydia test in females aged 12-60 years where the duration of infection was known. A positive result at a first visit was not considered as an incident case since the duration of infection was unknown. An individual was classified as having an incident infection if either a positive test with a previous positive or negative test result had been documented at least 30 days earlier. ${ }^{78}$ In our sample we assumed repeat chlamydia positive PCR tests $>30$ days apart represented incident infections since PCR chlamydia tests have not been found to remain positive for longer than 3 weeks following therapy and both a 7 day course of doxycycline and a single dose azithromycin have treatment failure rates $\leqslant 5 \%$ at 2-4 weeks after therapy. ${ }^{19-21}$

\section{DATA ANALYSIS}

Data were entered into a computer database (d-base III, plus, Ashton Tate, Borland International, Inc, Scotts Valley, CA, USA). All statistical analyses were performed using Intercooled Stata 5.0 (Stata Corporation, College Station, TX, USA).

To clearly characterise the chlamydia burden in the study population for the period 1 January 1994 to 30 September 1996, we calculated four distinct prevalence rates. Prevalence rate was calculated as: (1) the proportion of chlamydia positive test results among all chlamydia tests (2) the proportion of females with at least one positive chlamydia test, (3) the proportion of first chlamydia tests that were positive, and (4) the proportion of repeat chlamydia tests that were positive during the observational period. $^{722}$

Incidence was calculated as the rate of incident cases per person month of exposure among females with $>1$ clinic visit. The person months were calculated as the sum of time at first test to time at last test for each patient during the study period. Clinic based incidence 


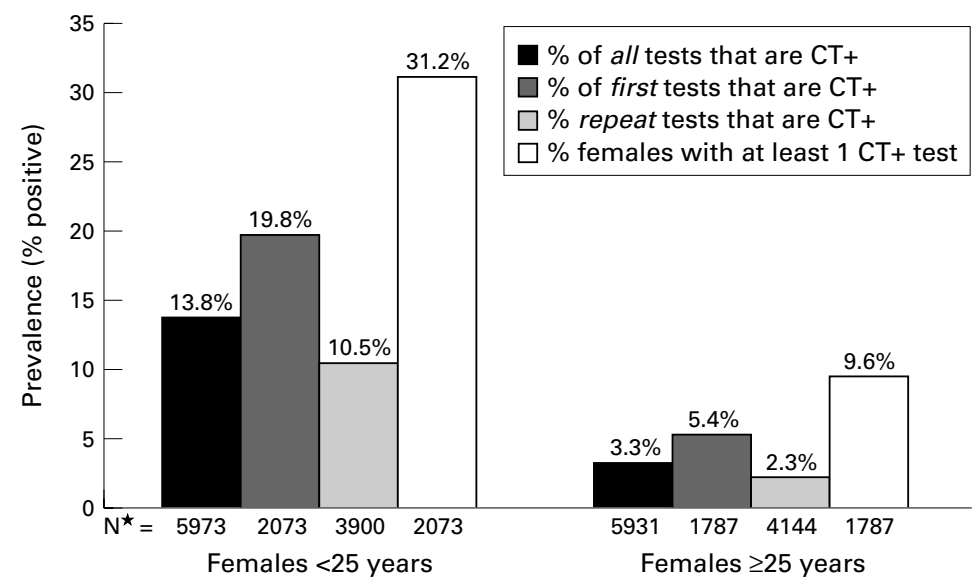

Figure 1 Chlamydia trachomatis prevalence rates with polymerase chain reaction testing by age. ${ }^{\star}$ Number of visits.
Females tested

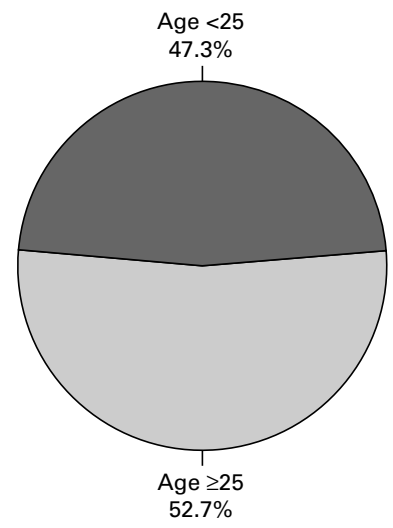

$N=10890$ visits
Females infected

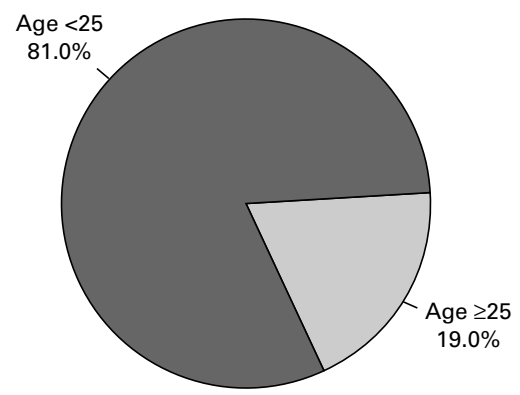

$\mathrm{N}=1040$ visits
Figure 2 Proportion of clinic visits with polymerase chain reaction tests for Chlamydia trachomatis and test results among females by age.

rates were adjusted for age. A 95\% confidence interval for the incidence rate was calculated under the assumption of an exponential distribution for time to disease using a maximum likelihood estimate of variance. ${ }^{23}$

The frequency of diagnosis of first incident infection was estimated by calculating the median time interval in months between first test and first positive test during the study period among all females with negative results at first test and at least one subsequent positive test. $^{7}$ The frequency of diagnosis of repeat incident infection was estimated by calculating the median time interval in months between first and repeat positive test during the study period among all females with at least two positive tests.

Patterns of none, one, or $>1$ positive chlamydia PCR test result obtained with a cervical or urine specimen during the course of the study period were the dependent variables. Independent variables at first visits analysed as possible predictors of chlamydia PCR test result patterns included age $(<25$ or $\geqslant 25$ years), reason for clinic visit, clinic type, history of STDs, condom use, new sex partners, and multiple sex partners. Association between each of these clinical and behavioural variables with infection was evaluated by bivariate analysis using Pearson's $\chi^{2}$ test of independence. All independent variables found significant $(p<0.05)$ in the bivariate analysis were entered into a multinomial logistic regression model to estimate the adjusted relative risks of one or of repeat chlamydia diagnoses compared with no diagnosis of infection. A significance level of less than 0.05 was specified for variables to remain in the model.

\section{Results}

STUDY SAMPLE

The 11904 patient visits $>30$ days apart were made by 3860 females aged 12-60 years over the 33 month period. The mean age of females at clinic visit was 25.7 (SD 8.2) years and 97\% were African-American. The mean number of clinic visits per individual was 3.1 (1.5), and the median time to a repeat visit was 4.2 months. These time dimensions did not vary with age (that is, age $<25$ years versus $\geqslant 25$ years). Forty two per cent of visits were to FP, $45 \%$ were to STD, and $7 \%$ were to school based clinics, which are utilised predominantly by an urban community with limited financial resources. More than $75 \%$ of females admitted to inconsistent condom use and over $85 \%$ claimed only one sex partner during the 90 days before the time of first clinic visit (table 1).

\section{CHLAMYDIA PREVALENCE AND INCIDENCE}

During the study period, $8.5 \%$ of all chlamydia tests performed on the $12-60$ year old sexually active females were positive. Chlamydia prevalence distinctly varied by age. Among females $<25$ years, chlamydia infection was found in $821(13.8 \%)$ of all clinic visits. Almost $20 \%$ of the 2073 first tests and $10.5 \%$ of the 3900 repeat tests were positive. Overall, a third of the 2073 females <25 years had at least one positive chlamydia test (fig 1). In contrast, among females $\geqslant 25$ years, $193(3.3 \%)$ of chlamydia tests were positive. For females $\geqslant 25$ years, chlamydia infection was found in $5.4 \%$ of the 1787 first tests and $2.3 \%$ of the 4144 repeat tests. Of the 1787 females $\geqslant 25$ years in the sample, approximately $10 \%$ had at least one positive test (fig 1). Females $<25$ years accounted for $81 \%$ of all the positive chlamydia tests in the sample (fig 2).

The chlamydia incidence rate and frequency of incident infection also varied by age (table 2). Among females $<25$ years, the chlamydia incidence rate was 20.3 cases per 1000 person months based on 378 incident chlamydia infections detected during 18626 person months of observation (95\% confidence interval 18.4-22.5). This was substantially higher than the rate for females $\geqslant 25$ years of 3.6 cases per 1000 person months based on 88 incident chlamydia infections detected during 24227 person months of observation (95\% CI 2.94.4). Chlamydia incidence varied to a lesser degree by clinic type. Age adjusted incidence for FP clinics was 10.0 cases per 1000 person months of observation (95\% CI 9.5-10.5), for STD clinics was 13.5 cases per 1000 person 
Table 2 Time dependent $C$ trachomatis infection rates among 3860 sexually active females at 11904 clinic visits >30 days apart diagnosed by PCR in Baltimore, MD, family planning, sexually transmitted diseases, and school based clinics, fan 1994-Sept 1996

\begin{tabular}{llcc}
\hline $\begin{array}{l}\text { Age } \\
\text { (years) }\end{array}$ & $\begin{array}{l}\text { Incidence* (95\% CI) } \\
\text { (person months) }\end{array}$ & $\begin{array}{l}\text { Time to first infectiont } \\
(25 \%-75 \%) \text { (months) }\end{array}$ & $\begin{array}{c}\text { Time to repeat infectiont } \\
(25-75 \%) \text { (months) }\end{array}$ \\
\hline$<25$ & $20.3(18.4-22.5)$ & $7.0(4.1-11.1)$ & $7.6(5.0-12.3)$ \\
$\geqslant 25$ & $3.6(2.9-4.4)$ & $13.8(6.3-18.3)$ & $11.0(4.2-18.3)$ \\
\hline
\end{tabular}

${ }^{\star}$ Cases per 1000 person months. †Incident infections.

months of observation (95\% CI 12.4-14.6), and for school based clinics was 21.4 cases per 1000 person months of observation (95\% CI 9.5-10.5).

The frequency of diagnosis of incident infection for females $<25$ years was almost twice that of females $\geqslant 25$ years. Following at least one negative chlamydia test, the median time to a first positive chlamydia test was 7.6 months (interquartile range 5.0-12.3 months) for females $<25$ years compared with 13.8 months (interquartile range 6.3-18.3 months) for females $\geqslant 25$ years. The median time to a repeat positive chlamydia test was 7.0 months (interquartile range 4.1-11.1 months) for females $<25$ years in contrast with 11.0 months (interquartile range $4.2-18.3$ months) for females $\geqslant 25$ years.

RELATIVE RISKS OF INFECTION

Relative risk ratios for diagnosis of one and repeat $(>1)$ chlamydia infections during the 33 month study period compared with obtaining all negative test results are shown in table 3 . Variables at first clinic visit identified by multinomial logistic regression to be independently associated with a female having one positive chlamydia tests during the study period included age $<25$ years, being seen at an STD clinic compared with a school based clinic, clinic visit for "other" reason compared with screening as reason for clinic visit, and inconsistent condom use (table 3). Paradoxically in this model, having a previous syphilis infection was protective even after controlling for age.

Variables at first clinic visit identified by multinomial logistic regression to be independ- ently associated with a female having at least one repeat positive test compared with all negative chlamydia tests during the study period included age $<25$ years, being seen at an STD clinic compared with a school based clinic, and clinic visit for "other" reason compared with screening as reason for clinic visit (table 3 ).

Age $<25$ years was the strongest predictor of infection and of reinfection. The relative risk of a female having one positive chlamydia test result compared with all negative test results during the study period was 4.0 (95\% CI 3.34.9) for females $<25$ years relative to females $\geqslant 25$ years. Even more pronounced was the risk of repeat infections with young age. The relative risk of a female having repeat positive chlamydia test results compared with all negative test results during the study period was 8.9 (95\% CI 5.6-14.3) for females $<25$ years relative to females $\geqslant 25$ years.

In our sample, age $<25$ years was the most effective screening criterion to define a group of females with the majority of infections. The other chlamydia risk factors were present in only a small proportion of first clinic visits by females with $\geqslant 1$ positive test result during the study period or present for all females at first visit, regardless of chlamydia test results (tables 1 and 4). For example, if a chlamydia screening programme targeted all females $<25$ years, only $53 \%$ of females would be screened (table 1) while $77 \%$ of those with one positive test and $87 \%$ of those with repeat positive tests during the study period would have been identified (table 4). In the situation where chlamydia screening was performed for all females who admitted to $>1$ sex partner at their first visit, screening would have been rendered for only $14 \%$ of females in the sample (table 1), resulting in lower total screening costs incurred. However, $84 \%$ of females with one positive and $81 \%$ of females with $>1$ positive test would have been missed (table 4 ). But if chlamydia screening was performed for all females where inconsistent condom use was identified at the first clinic visit as a risk factor,

Table 3 Relative risk ratios of $C$ trachomatis PCR test result patterns dependent on variables in first visit by multivariate analysis

\begin{tabular}{|c|c|c|c|c|c|}
\hline \multirow[b]{2}{*}{ Variable } & \multicolumn{5}{|c|}{ Relative risk of test result patterns ${ }^{\star}$ for adjusted variables of interest } \\
\hline & $\begin{array}{l}\text { All negative } \\
(n=3043) \text { RRRt }\end{array}$ & $\begin{array}{l}1 \text { Positive }(n=650) \\
\operatorname{RRR}(95 \% \mathrm{CI})\end{array}$ & $p$ Value & $\begin{array}{l}>1 \text { Positive }(n=167) \\
R R R(95 \% C I)\end{array}$ & p Value \\
\hline \multicolumn{6}{|l|}{ Age (years) } \\
\hline$<25$ & 1 & $4.0(3.3-4.9)$ & $<0.001$ & $8.9(5.6-14.3)$ & $<0.001$ \\
\hline$\geqslant 25$ & 1 & 1 & & 1 & \\
\hline \multicolumn{6}{|l|}{ Reason for clinic visit } \\
\hline STD contact & 1 & $1.1(0.8-1.6)$ & 0.4 & $1.3(0.8-2.2)$ & 0.3 \\
\hline STD symptoms & 1 & $1.1(0.9-1.5)$ & 0.3 & $1.1(0.7-1.7)$ & 0.8 \\
\hline "Other" & 1 & $1.8(1.2-2.7)$ & 0.005 & $2.2(1.1-4.3)$ & 0.02 \\
\hline Screening & 1 & 1 & & 1 & \\
\hline \multicolumn{6}{|l|}{ Clinic type } \\
\hline Family planning & 1 & $1.3(0.9-1.9)$ & 0.1 & $1.6(0.8-3.0)$ & 0.1 \\
\hline STD & 1 & $1.6(1.1-2.3)$ & 0.007 & $2.2(1.2-4.2)$ & 0.01 \\
\hline School & 1 & 1 & & 1 & \\
\hline \multicolumn{6}{|l|}{ Risk behaviours } \\
\hline Inconsistent condom use & 1 & $1.3(1.0-1.6)$ & 0.04 & $1.2(0.8-1.9)$ & 0.3 \\
\hline$>1$ sex partner & 1 & $1.1(0.9-1.5)$ & 0.4 & $1.5(0.9-2.4)$ & 0.09 \\
\hline New sex partner & 1 & $1.1(0.8-1.4)$ & 0.5 & $0.9(0.5-1.4)$ & 0.6 \\
\hline \multicolumn{6}{|l|}{ Self reported STD history } \\
\hline Previous syphilis infection & 1 & $0.4(0.2-0.8)$ & 0.008 & $0.9(0.3-2.2)$ & 0.8 \\
\hline
\end{tabular}

*Compared with all negative test results.

$\dagger R R R=$ relative risk ratio; $C I=$ confidence interval. 
Table 4 Association between variables at first visit and $C$ trachomatis PCR test result patterns by bivariate analysis

\begin{tabular}{|c|c|c|c|c|}
\hline \multirow[b]{2}{*}{ Variable } & \multicolumn{3}{|c|}{ Test result patterns } & \multirow[b]{2}{*}{$p$ Value } \\
\hline & $\begin{array}{l}\text { All negative } \\
(\%)(n=3043)\end{array}$ & $\begin{array}{l}1 \text { Positive* }(\%) \\
(n=650)\end{array}$ & $\begin{array}{l}>1 \text { Positive* } \\
(\%)(n=167)\end{array}$ & \\
\hline \multicolumn{5}{|l|}{ Age (years) } \\
\hline$<25$ & 46.5 & 77.1 & 87.4 & \multirow[t]{2}{*}{$<0.001$} \\
\hline$\geqslant 25$ & 53.5 & 22.9 & 12.6 & \\
\hline \multicolumn{5}{|l|}{ Reason for clinic visit } \\
\hline STD contact & 12.6 & 13.8 & 16.8 & $<0.05$ \\
\hline STD symptoms & 21.7 & 24.5 & 23.3 & \\
\hline "Other" & 3.6 & 6.5 & 7.8 & \multirow[t]{2}{*}{$<0.001$} \\
\hline Screening & 62.1 & 55.2 & 52.1 & \\
\hline \multicolumn{5}{|l|}{ Clinic type } \\
\hline Family planning & 44.7 & 37.6 & 34.1 & 0.02 \\
\hline STD & 48.0 & 53.2 & 57.5 & \multirow[t]{2}{*}{0.7} \\
\hline School & 7.3 & 9.2 & 8.4 & \\
\hline \multicolumn{5}{|l|}{ Risk behaviours } \\
\hline Inconsistent condom use & 74.5 & 79.4 & 80.2 & 0.01 \\
\hline$>1$ sex partner & 12.9 & 15.7 & 19.2 & 0.02 \\
\hline New sex partner & 13.6 & 17.5 & 17.4 & 0.02 \\
\hline \multicolumn{5}{|l|}{ Self reported STD history } \\
\hline Previous syphilis infection & 4.5 & 1.5 & 3.0 & 0.002 \\
\hline Previous GC/CT $†$ infection & 37.3 & 34.5 & 39.5 & 0.3 \\
\hline
\end{tabular}

${ }^{\star}$ Number of C trachomatis PCR test results during Jan 1994-Sep 1996.

†GC $=$ Neisseria gonorrhoeae $; \mathrm{CT}=$ Chlamydia trachomatis .

$80 \%$ of females diagnosed with $\geqslant 1$ infection would have been identified (table 4), but screening would have been indicated for three quarters of females in the sample (table 1), offering little advantage to selective screening. Thus, age $<25$ years offered the best selective screening criterion upon which to based targeted testing.

\section{Discussion}

Chlamydia screening programmes have been successful at reducing the incidence and prevalence of infection. ${ }^{924}$ Because broad scale screening is expensive, STD epidemiologists have attempted to identify demographic and behavioural risk factors to develop selective chlamydia screening criteria. ${ }^{19} 2627$ We found that age was the most important predictor of chlamydia infection and reinfection. In our sample of almost 4000 sexually active females, screening only those age $<25$ years (half of our population) would have identified nearly $80 \%$ of females diagnosed with $\geqslant 1$ chlamydia infections. The relative risk of diagnosis of one chlamydia infection during the study period for females $<25$ years was four times that of females $\geqslant 25$ years and for recurrent infection was nine times of that of females $\geqslant 25$ years. All other predictors imparted incomparably modest, if any, risks of infection and reinfection. Other studies utilising less sensitive chlamydia tests and smaller study samples have also found recurrent chlamydia infections within 5-9 month periods among their adolescent female patients. $^{28} 29$

Age as a selective chlamydia screening criteria offers many practical operational advantages to chlamydia programmes and is nonjudgmental. As an objective criterion, it avoids potential response to bias to sexual behaviour questions. In addition, age can be used as a convenient, easily defined indicator for quality assurance measures. Although providers have historically relied on complaints of STD symptoms as a sensitive screening tool for females, a high proportion of chlamydia infected females in our study denied symptoms suggestive on an STD. Chlamydia infected females may be ashamed to admit STD related symptoms to providers or may not perceive their symptoms as signs of infection. Both public and private healthcare sectors continually search for cost effective strategies to deliver quality care. Age based universal screening and urine based DNA amplification testing have proved to be cost effective chlamydia screening strategies. ${ }^{11} 3031$

We found paradoxically that syphilis was "protective" for chlamydia. We believe that in reality, this represents a spurious finding because of confounding by age. The majority of females diagnosed with syphilis in Baltimore City are $\geqslant 25$ years of age, whereas chlamydia is a more common infection diagnosed in younger females (Noreen Hynes, personal communication).

Our study had several limitations. Firstly, the race, ethnicity, and socioeconomic status of our sample population were homogeneous. Some of our findings may not apply to populations with more diverse racial, ethnic, and socioeconomic backgrounds. Also, our rates of chlamydia infection were very high and conclusions drawn may not be generalisable to areas where lower rates of chlamydia exists. However, our chlamydia rates were determined using more sensitive tests than are available to many parts of the country, where the disease burden may be underestimated. ${ }^{32}$

A second limitation is our use of only a limited number of behavioural risk factors at first clinic visit as predictors of infection during the study period. Other risk factors, such as method, timing, and type (male versus female) of condom use, STD and HIV coinfection, sexual abuse, and partner age need to be examined. In addition, we relied on first visit behavioural risk factors, which may change over time, to predict occurrence of chlamydia diagnoses at first and subsequent visits. ${ }^{33-35}$ However, behavioural risk factors minimally contributed to our ability to predict risk of infection at current or future visits. Thus, we do not believe the reliability of our findings would be altered.

Males were not included in this sample, which is a current limitation of the CDC Infertility Prevention Project. The epidemiology of chlamydia infection in males differs from that of females, such as older age of peak infection rates and lower risk of sequelae, but data on this subject are limited. ${ }^{3-6}{ }^{36-42}$ The high recurrent infection rate in this study suggests an existing reservoir of asymptomatic male chlamydia infection.

A number of observations were not included in the data analysis owing to incomplete information on demographic and behavioural characteristics. These exclusions represented only $4.8 \%$ of the total number of observations. We therefore do not feel that these data would have altered our findings significantly. Also, females with only one clinic visit were not included in the analysis. However, age based chlamydia prevalence and predictors of infection did not 
significantly differ when the analysis included all females with $\geqslant 1$ clinic visit. ${ }^{43}$

Finally, history of infection status of these sexually active females diagnosed in clinics outside the study sites and at times after the study period is unknown. Females in this sample may have been diagnosed and treated for chlamydia infection at other clinical sites before, or during the study period. In addition, females may have been infected during the study period, but never tested or tested after the end of data collection. Thus, determination of true chlamydia history, incidence, and prevalence rates is limited to data available to us and may have resulted in an underestimation of the absolute rate of chlamydia infection.

Health defined as "physical, mental, and social wellbeing" includes the capacity for fertility and sexual pleasure. ${ }^{44}$ Since chlamydia can have a devastating impact on fertility and sexual health, appropriate screening of asymptomatic females improves capacities for good health. ${ }^{45}$ We found the chlamydia incidence rate for females $<25$ years to be more than five times greater than in females $\geqslant 25$ years and the median time to diagnosis of incident infection to be approximately half. Sexual risk and health seeking behaviours failed to effectively identify females at risk of infection and repeat infection during the study period. Therefore, we recommend screening ALL females $<25$ years for chlamydia twice a year regardless of symptoms, previous infections, condom use, or multiple partner risk.

This study was supported in part by a Centers for Disease Control and Prevention-Association of Teachers of Preventive Medicine STD Prevention Fellowship.

We wish to thank Nicole Novak, Kimberly Crotchfelt, Jennifer Grider, Region III staff, staff and clinicians at the Baltimore City family planning, sexually transmitted diseases, and school based clinics, and Baltimore City Health Department staff who based clinics, and Baltimore City Health Department staff who
helped make this study possible. We also thank Noreen Hynes, MD, for her review of the manuscript.

Contributors: All authors participated in the writing and approval of this article; GRB prepared the first draft of the paper and she and MDW conducted the data analysis and interpretation; JMZ and MRH contributed to data analysis and interpretation; CAG carried out the laboratory studies, she and WB liaised with clinics, supervised data collection, and management; TCQ initiated and developed the core ideas and study design and oversaw its execution.

1 Alexander LA, Cates JR, Herndon N, et al. Sexually transmitted diseases in America. Menlo Park, CA: Kaiser Family Foundation, December, 1998.

2 Division of STD Prevention. Sexually transmitted disease surveillance, 1997. US Department of Health and Human Services, Public Health Service. Atlanta: Centers for Disease Control and Prevention, September 1998.

3 World Organization Task Force on the Prevention and Management of Infertility. Tubal infertility: serologic relationship to past chlamydial and gonococcal infection. Sex Transm Dis 1995;22:71-6.

4 Kelver ME, Nagamani M. Chlamydial serology in women Kelver ME, Nagamani M. Chlamydial serolog
with tubal infertility. Int $\mathcal{f}$ Fertil 1989;34:42-5.

5 Henry-Suchet J, Utzmann C, De Brux J, et al. Microbiologic study of chronic inflammation associated with tubal factor infertility: role of Chlamydia trachomatis. Fertil Steril 1987; 47:274-7.

6 Chow JM, Yonekura L, Richwald GA, et al. The association between Chlamydia trachomatis and ectopic pregnancy. ҰAMA 1990;263:3164-7.

7 Burstein GR, Gaydos CA, Diener-West M, et al. Incident Chlamydia trachomatis infections among inner city adolescent females $\mathscr{f} A M A$ 1998;280:521-6.

8 Institute of Medicine. The neglected health and economic impact of STDs. In: Eng TR, Butler WT, eds. The hidden epidemic. Washington, DC: National Academy Press, 1997: 28-67.

9 Scholes D, Stergachis A, Heidrich FE, et al. Prevention of pelvic inflammatory disease by screening for cervical pelvic inflammatory disease by screening for cerv
chlamydial infection. $N$ Engl f Med 1996;334:1362-6.

10 Centers for Disease Control and Prevention. Recommendations for the prevention and management of Chlamydia trachomatis infections. MMWR 1993;42(RR-12).
11 Howell MR, Quinn TC, Brathwaite W, et al. Screening women for Chlamydia trachomatis in family planning clinics: the cost-effectiveness of DNA amplification assays. Sex Transm Dis 1998; 25:108-17.

12 Courtney J, Ellen J, Bolan G. Meta-analysis of the sensitivity and specificity of chlamydia diagnostic tests in females [Abstract No O263]. 12th Meeting of the International Society of Sexually Transmitted Diseases Research, 1997.

13 Quinn TC, Welsh L, Lentz A, et al. Diagnosis by Amplicor PCR of Chlamydia trachomatis infection in urine samples from women and men attending sexually transmitted disease clinics. F Clin Microbiol 1996;34:1401-6.

14 Schachter J, Moncada J, Whidden R, et al. Noninvasive tests for diagnosis of Chlamydia trachomatis infection: application for diagnosis of Chlamydia trachomatis infection: application
of ligase chain reaction of first-catch urine specimens in women. F Infect Dis 1995;172:1411-14.

15 Schachter J, Shafer MA, Young M, et al. Routine pelvic examinations in asymptomatic young women. [Letter] $N$ Engl F Med 1995;335:1847-8.

16 Orr DP. Urine based diagnosis of Sexually transmitted infections using amplified DNA techniques: a shift in paradigms? F Adol Health 1997;20:3-5.

17 Nathanson PG, Fine D, Braxton JR. Program implications of screening for chlamydia beyond family planning and STD clinics [Abstract No O248]. 12th Meeting of the International Society of Sexually Transmitted Diseases Research, Seville, Spain, 1997.

18 Zenilman JM, Weisman CS, Rompalo AM, et al. Condom use to prevent incident STDs: the validity of self-reported condom use. Sex Transm Dis 1995;22:15-21.

19 Gaydos CA, Crotchfelt KA, MR Howell, et al. Molecular amplification assays to detect chlamydia infections in urine specimens from high school female students and to monitor the persistence of chlamydial DNA after therapy. $f$ Infect Dis 1998; 177:417-24.

20 Thorpe EM, Stamm WE, Hook EW, et al. Chlamydial cervicitis and urethritis: single dose treatment compared with doxycycline for seven days in community based practices. Genitourin Med 1996; 72:93-7.

21 Hillis SD, Coles FB, Litchfield B, et al. Doxycycline and azithromycin for prevention of chlamydial persistence or recurrence one month after treatment in women. Sex Transm Dis 1998; 25:5-11.

22 Centers for Disease Control and Prevention. Chlamydia trachomatis genital infections-United States, 1995. MMWR 1997;46:193-8.

23 Selvin S. Statistical Analysis of Epidemiologic Data. Monographs in Epidemiology and Biostatistics. Vol 17. New York: Oxford Press, 1991:285.

24 Hillis SD, Black K, Newhall J, et al. New opportunities for chlamydia prevention: applications of science to public health practice. Sex Transm Dis 1995;22:197-202.

25 Wasserheit JN, Aral SO. The dynamic topology of sexually transmitted disease epidemics: implications for prevention transmitted disease epidemics: implications for preven
strategies. F Infect Dis 1996;174(Suppl 2):S201-13.

26 Handsfield HH, Jasman LL, Roberts PL, et al. Criteria for selective screening for Chlamydia trachomatis infection in women attending family planning clinics. $\mathcal{F} A M A 1986 ; 255$ : 1730-4.

27 Stergachis A, Scholes D, Heidrich FE, et al. Selective screening for Chlamydia trachomatis infection in a primary care population of women. Am F Epidemiol 1993;138:14353.

28 Fortenberry JD, Evans DL. Routine screening for genital chlamydia trachomatis in adolescent females. Sex Transm Dis 1989;16:168-72.

29 Blythe MJ, Katz BP, Batteiger BE, et al. Recurrent genitourinary chlamydial infections in sexually active genitourinary chlamydial infections in sexual

30 Howell MR, Quinn TC, Gaydos CA. Screening for Chlamydia trachomatis in asymptomatic women attending family planning clinics. Ann Intern Med 1998;128:277-84.

31 Shafer MAB, Pantell RH, Schachter J. Is the routine pelvic examination needed with the advent of urine-based screening for sexually transmitted diseases? Arch Pediatr Adolesc Med 1999;153:119-25.

32 Schacter J. Chlamydia trachomatis: the more you look, the more you find-how much is there? [Editorial] Sex Transm Dis 1998;25:229-31.

33 Orr DP, Langefeld CD, Katz BP, et al. Behavioral intervention to increase condom use among high-risk female adolescents. F Pediatr 1996;128:288-95.

34 Fortenberry JD, Orr DP, Zimet GD, et al. Weekly and seasonal variation in sexual behaviors among adolescent
women with sexually transmitted diseases. 7 Adol Health 1997;20:420-5.

35 Howard MM, Fortenberry JD, Blythe MJ, et al. Patterns of sexual partnerships among adolescent females. $\mathcal{F}$ Adol Health 1999;24:300-3.

36 Burstein, GR, Waterfield G, Hauptman P, et al. Chlamydia screening by urine based DNA amplification in adolescent
males attending school based health centers [Abstract]. $\mathcal{F}$ Adol Health 1999;24:120.

37 Burstein GR, Zenilman JM. Non-gonococcal urethritis-a new paradigm. Clin Infect Dis 1999;28(Supp1 1):S66-73.

Cohen D, Nsuami M, Etame RB, et al. A school-based chlamydia control program using DNA amplification technology. Pediatrics 1998;101:e1.

39 Rietmeijer CA, Yamaguchi KJ, Oritz CG, et al. Feasibility and yield of screening urine for Chlamydia trachomatis by polymerase chain reaction among high-risk male youth in 1997;24:429-35. 
40 Marrazzo JM, White CL, Krekeler B, et al. Communitybased screening for Chlamydia trachomatis with a ligase chain reaction assay. Ann Intern Med 1997;127:796-803.

41 Ness RB, Markovic N, Carlson CL, et al. Do men become infertile after having sexually trasnmitted urethritis? An epidemiologic examination. Fertil Steril 1997;68:205-13.

42 Eggert-Kruse W, Buhlinger-Gopfarth N, Rohr G, et al. Antibodies to Chlamydia trachomatis in semen and relationship with parameters of male fertility. Hum Reprod 1996;11:1408-17. 43 Burstein GR, Gaydos CA, Diener-West $M$, et al. Predictors
of C trachomatis infection by polymerase chain reaction among females presenting to US inner city clinics. Poster presentation at the International Conference on Sexually Transmitted Diseases, Seville, Spain, October, 1997.

44 World Health Organization. Basic documents. 35th ed. Geneva: WHO, 1985.

45 Stamm WE. Chlamydia trachomatis infections in the adult. In: Homes KK, Sparling PF, Mardh PA, et al, eds. Sexually In. Homes KK, Sparling PF, Mardh PA, et al, eds. Sexually 407-22.

46 Breslow L. From disease prevention to health promotion. fAMA 1999;281:1030-3 